\title{
ERRATUM
}

G. Battista $\cdot$ P. Comba - D. Orsi - K. Norpoth · A. Maier

\section{Nasal cancer in leather workers: an occupational disease}

Received: 5 August 1994 / Accepted: 28 August 1994

On p. 2, right column, the number of cases was misprinted (1975 instead of 66) in the second paragraph. It should read as follows:

In Western Germany between 1979 and 1984 altogether 66 cases of sinonasal adenocarcinomas were reported from more than 160 hospitals (Grimm et al. 1984; Wolf et al. 1986). The evaluation of potential occupational causes suggested a strong influence of wood dust exposure but in no case of adenocarcinoma could exposure to leather dust be found in the working histories. This lack of evidence may be due to a very low risk in Western Germany.

G. Battista $(\varangle) \cdot$ D. Orsi

Unit of Workers' Preventive Medicine, University of Siena, Via Tufi 1, I-53100 Siena, Italy

P. Comba

Istituto Superiore di Sanita, Rome, Italy

K. Norpoth · A. Maier

Institut für Hygiene und Arbeitsmedizin, Universitätsklinikum, Essen,

Germany 